\title{
Severe abdominal pain in a septic child post open appendicectomy
}

\author{
Adam O'Connor ${ }^{1}$, Shariq Sabri ${ }^{2}$, and Alhad Dhebri ${ }^{2}$
}

${ }^{1}$ Affiliation not available

${ }^{2}$ Tameside General Hospital

May 26, 2020

\begin{abstract}
Post appendicectomy abscess formation is uncommon in patients with non-perforated appendicitis. Diagnosis via imaging is essential to provide swift treatment and resolution of underlying infection, which we demonstrate in our case.

Severe abdominal pain in a septic child post open appendicectomy

'Clinical images' submission to Wiley Clinical Case Reports Journal

Author List

Dr Adam O'Connor, Core surgical trainee, Department of General surgery, Tameside General Hospital, Manchester, UK

Mr Shariq Sabri, specialty doctor, Department of General surgery, Tameside General Hospital, Manchester, UK

Mr Alhad Dhebri, Consultant surgeon, Department of General Surgery, Tameside General Hospital, Manchester, UK
\end{abstract}

\section{Corresponding author:}

Dr Adam O'Connor, Core Surgical Trainee, Tameside General Hospital, Manchester, UK

Apartment 918, Torrens Apartments, Clippers Quay, Salford Quays, M50 3AT

Ao1112@my.bristol.ac.uk

Keywords

'abscess'

'appendicectomy'

'paediatric'

'surgery'

Key Clinical Message

Post appendicectomy abscess formation is uncommon in patients with non-perforated appendicitis. Diagnosis via imaging is essential to provide swift treatment and resolution of underlying infection, which we demonstrate in our case. 
An 8 year old female presented 7 days post open appendicectomy for acute uncomplicated appendicitis. Initial procedure was unremarkable, with no perforation seen macroscopically or microscopically. She appeared acutely unwell and was pyrexial and vomiting with severe lower abdominal pain. Examination of the abdomen revealed guarding and rigidity in the right iliac fossa and suprapubic regions. C reactive protein was raised at $282 \mathrm{~g} / \mathrm{L}$, white cell count was $24 \mathrm{X} 10^{\wedge} 9 / \mathrm{L}$. Computed tomography of the abdomen revealed a $7 \times 5 \mathrm{~cm}$ multiseptated and multiloculated abscess in the right iliac fossa with compression of the urinary bladder(Figure 1, Figure 2). The patient was transferred to a regional paediatric facility for laparotomy and washout.

Post open appendicectomy intrabdominal abscess incidence has previously been reported at around $2.5 \%$ in acute appendicitis, rising to $4.2 \%$ in perforated appendicitis(1). Indeed overall incidence of post appendicectomy abscess has been reported as higher in laparoscopic appendicectomy rather than open with figures as high as $6.4 \%$ for simple appendicitis and $24 \%$ for perforated appendicitis(1). These images convey the importance of considering early imaging in paediatric patients presenting post appendicectomy, as even in cases where contamination was minimal, there is a chance of deep seated abscess leading to intrabdominal sepsis and potential need for laparotomy.

Author Contributions

Dr Adam O'Connor-drafted report, initiated idea to write report, directly involved with patient case

Mr Shariq Sabri -helped with writing of report and proof reading/formatting

Mr Alhad Dhebri -responsible clinician for the patient in our case, supervised project

References

Krisher SL, Browne A, Dibbins A, Tkacz N, Curci M. Intra-abdominal Abscess After Laparoscopic Appendectomy for Perforated Appendicitis. Arch Surg. 2001;136(4):438-441.

Figure legends

Figure 1 - coronal computed tomography image demonstrating right iliac fossa abscess measuring $5 \times 7 \mathrm{~cm}$, multiloculated in nature and pressing on the urinary bladder

Figure 2 - sagittal computer tomography image again demonstrating the pelvic abscess

\section{Acknowledgements}

Many thanks to Dr S Jagath, consultant radiologist at Tameside General Hospital who provided the initial $\mathrm{CT}$ report on the case

\section{Conflict of interests}

All 3 authors report no conflicts of interest

Patient and parental consent was gained for the purpose of writing this article and is available on request. 


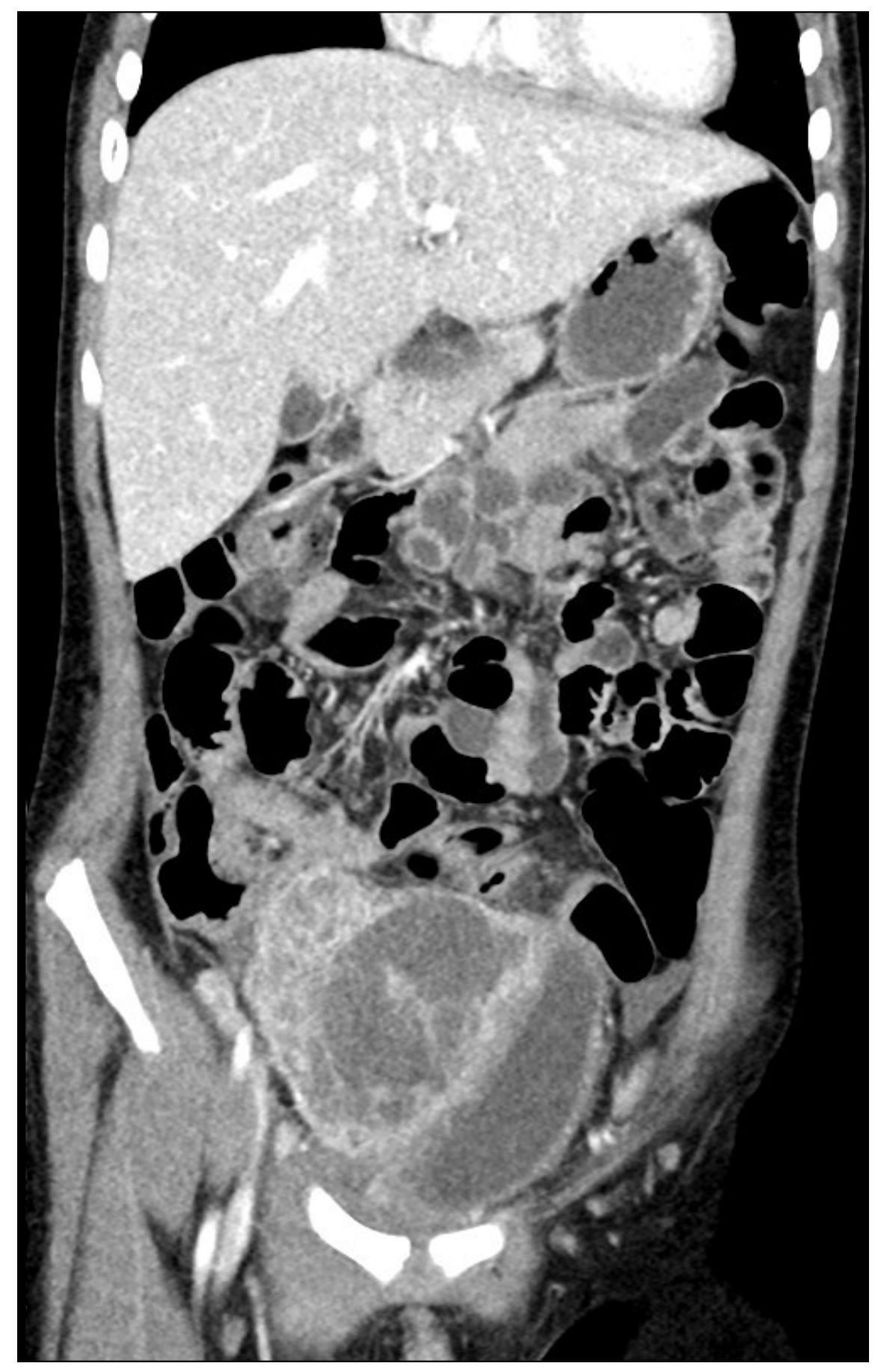




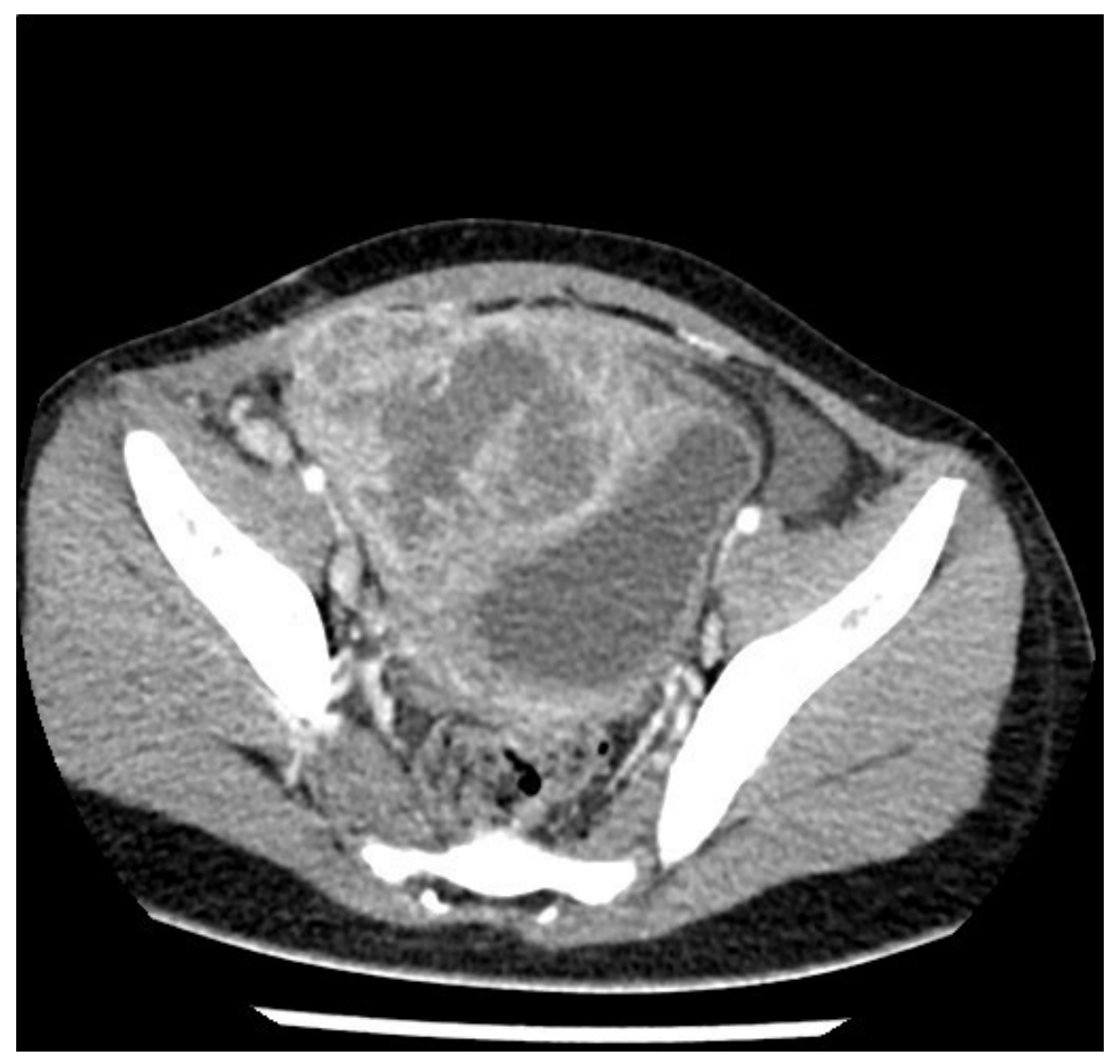

